\title{
El derecho, los sujetos encarnados y la experiencia social
}

\section{The right, embodied subjects and social experience}

Kathya Araujo*

\begin{abstract}
Resumen: Este artículo sostiene que el estudio de la expansión del ideal normativo de derecho en nuestra región debe trascender una perspectiva jurídica e institucional para poner el foco en las relaciones de los individuos con la norma propias a cada sociedad. El artículo presenta una propuesta teórica y metodológica para este abordaje así como su puesta a prueba a partir de los resultados obtenidos en una investigación empírica en el caso de Chile. El texto pone el acento en los efectos societales y en las configuraciones de sujeto diferenciales que resultan del encuentro del ideal normativo de derecho y las experiencias sociales propias a los individuos de esta sociedad.
\end{abstract}

Palabras-claves: Derecho; Relación con la norma; Individuos; Experiencias sociales

\begin{abstract}
This article argues that the study of the expansion of the normative ideal of law in our region must go beyond legal and institutional perspective to put the focus on relationships between individuals and the rule that are specific to each society. The paper presents a theoretical and methodological proposal for this approach and tests them with the results of an empirical investigation in Chile. The text emphasizes the societal effects and differential configurations of the subject that result of the meeting of the normative ideal of law and the specific social experiences of the individuals in this society.
\end{abstract}

Keywords: Law; Relationship with the norm; Individuals; Social experiences

En la actualidad el derecho se presenta como uno de los ideales regulatorios más extendidos de la vida social al punto de convertirse en un verdadero ideal normativo (Habermas, 1998). Esta función de ideal y sus efectos discursivos

* Doctora en Estudios Americanos por la Universidad de Santiago de Chile, profesora en la Universidad Academia de Humanismo Cristiano, Santiago, Chile; fué becaria ThyssenHumboldt; autora de libros como Habitar lo social: usos y abusos en la vida cotidiana en el Chile actual (LOM Ediciones) y Dignos de su arte. sujeto y lazo social en el Peru de las primera s decadas del siglo XX (Iberoamericana).<kathyaaraujo@yahoo.com.ar>.

\begin{tabular}{|l|l|l|l|l|l|}
\hline Civitas & Porto Alegre & v. 9 & n. 3 & p. 418-439 & set.-dez. 2009 \\
\hline
\end{tabular}


y procedimentales se revelan en fenómenos como la creciente juridización de la vida social (Habermas, 1987), la judicialización de los conflictos sociales y políticos, la ciudadanía como clave de lectura política (O'Donnell, 2002), entre otros. Una difusión, que, ciertamente, ha seguido trayectorias temporales y morfológicas desiguales y diversas según los contextos socio-históricos y culturales.

En consonancia con lo que ocurre en otros países, la noción de derecho se instala con inusitada fuerza en las últimas décadas como una propuesta de regulación de relaciones sociales en Chile. Se trata de una instalación que ha sido resultado de la acción combinada de por lo menos tres actores distintos pero abrevados en fuentes que confluyen: el estado, la sociedad civil organizada y los organismos internacionales (Araujo, 2009c; Drake y Jaksic, 2002; Toloza y Lahera, 1998; Garretón, 2000; De la Maza, 2002). Un proceso que, por otro lado, se presenta entretejido de manera explícita e implícita con los esfuerzos de modernización y consecuente democratización de las relaciones sociales en América Latina (Sorj y Martuccelli, 2008), las que tradicionalmente han estado asociadas con principios jerárquicos y con una crónica desregulación de las relaciones de poder.

La perspectiva más extendida en la región en el estudio de la expansión del ideal normativo de derecho, esto es su participación efectiva en el establecimiento de los principios regulatorios de las relaciones al interior de la sociedad, ha sido aquella que ha puesto el acento en la dimensión normativa e institucional (Smulovitz, Urribarri, 2007; Méndez, O’Donnell, Pinheiro, 2002; entre otros). La transformación de los cuerpos jurídicos, los procesos de modificación de la institucionalidad estatal, las formas de ejercicio de la justicia, la efectividad del estado de derecho o las modalidades y trayectos en la reestructuración de la o las ciudadanías, han sido temas en torno a los cuales se ha desarrollado una vasta y muy rica producción. A pesar del aporte de esta perspectiva, ella muestra sus límites. De manera relevante para nuestro argumento, una frontera de este abordaje reside en que ha tendido a entender la regulación social prioritariamente como efecto de un adecuado funcionamiento de las instituciones y la dimensión normativa, y ello por tres razones complementarias aunque de diferente orden.

Primero, porque no recoge suficientemente el hecho que la realidad social es un conjunto complejo de relaciones y dinámicas y que ella no puede ser entendida como un exacto reflejo de la dimensión normativa (Costa et al., 2009). Segundo, expresado en los términos de esta discusión, porque no toma en consideración en todas sus consecuencias que las relaciones sociales no son un mero efecto del estado de derecho sino que el estado de derecho es 
él mismo actualización, es decir efecto producido en las relaciones sociales. Tercero, porque deja fuera un aspecto que no por evidente ha resultado menos desatendido: que es necesario un sujeto para sostener y aún hacer existir cualquier orden normativo. El acento en la dimensión normativa institucional deja fuera la pregunta por el sujeto, no abstracto sino encarnado en un individuo empíricamente discernible, aquel indispensable para sostener un orden normativo tal.

Para decirlo en breve: estudiar los procesos vinculados a los derechos, la democratización, o la ciudadanía no puede reducirse a interrogar la dimensión institucional o normativa sino que debe incluir a los individuos y su relación con las normas. El orden normativo es movilizado, actualizado, sostenido o erosionado por individuos concretos en interacción con otros individuos e instituciones (Girola, 2005). Es necesario, entonces, hacerse cargo de esta entrada analítica formulando la pregunta por el orden de derecho ahora enfocándose en los individuos, aquellos que es necesario estudiar para arribar a la inteligencia de un orden normativo en su acción efectiva en la regulación de las relaciones sociales. Es esta vía por la que transita este artículo.

La perspectiva adoptada aquí, la que se centra en recoger los modos en que el ideal normativo es movilizado por individuos concretos, se pregunta por el grado y la forma en que este ideal puede ser herramienta en la comprensión, evaluación y legitimación de sí mismos en lo social, una medio privilegiado para formular el principio de respeto (Taylor, 1996, p. 25), y partícipe en las modalidades de dar contenido a las relaciones efectivas entre individuos y estos y las instituciones. Vale la pena insistir: no se trata de una perspectiva que piensa al individuo desde el registro normativo, filosófico-político abstracto y desencarnado del sujeto de derecho, sino de una perspectiva sociológica y psicosocial que se pregunta por la manera en que el ideal normativo de derecho participa en modelar la interpretación y acción de sujetos encarnados en individuos empíricamente discernibles.

De esta manera, el ideal normativo de derecho interesa en cuanto participa o no en la constitución de las claves de lectura privilegiadas de los intercambios en lo social así como en la medida en que da cuenta del tipo de sujetos que se producen en el contexto de la relación de los individuos con la norma. Este texto presenta este enfoque de estudio en acción a partir de los resultados de una investigación realizada para el caso de Chile. ${ }^{1}$ La línea argumental contempla tres pasos. Primero, se desarrolla la propuesta teórico

Esta investigación se realizó en dos etapas entre el 2003 y 2006 y fue posible gracias al apoyo de Oxfam Gran Bretaña. Mi agradecimiento a Carolina Ibarra, Claudia Moreno, María Elena Fuentes por su aporte en la realización de la investigación. 
conceptual utilizada para abordar el problema de la relación del individuo con las normas, la que ha sido cincelada al calor del encuentro con el material en un programa de investigación de varios años. Segundo, describir brevemente la investigación y el procedimiento metodológico para la producción del material. Tercero, discutir desde la perspectiva de la relación de los individuos con las normas, los resultados obtenidos sobre el funcionamiento del ideal normativo de derecho y sus efectos en la regulación social en el caso chileno.

\section{La configuración de sujeto: entre ideal y experiencia}

Para la comprensión de la relación de los individuos con las normas resulta indispensable considerar que los procederes individuales no pueden ser entendidos como consecuencia directa de la acción del ideal normativo abstracto. Un proceder no se encuentra en una relación lineal con las prescripciones que la norma impone. Esto es extremadamente importante porque generar una línea de lectura de la conducta a partir de su distancia $o$ cercanía al ideal conduce a una interpretación y evaluación "normativista" de la realidad social que pone el acento en el déficit de los individuos o de las sociedades. ${ }^{2}$ Cuando ésta es la opción, la consecuencia es que se velan las lógicas propias de cada sociedad y de los modos en que sus individuos establecen sus relaciones con las normas.

Pero, al mismo tiempo, las conductas de los individuos no pueden explicarse tampoco como un mero resultado de la acción - reacción pragmática frente a una realidad social que los empuja en ciertas direcciones. Cuando la conducta es entendida principalmente como una respuesta a las condiciones sociales o ambientales, ${ }^{3}$ queda abierta la pregunta por el espacio de elaboración propia al actor (Taylor, 1996).

Es por lo tanto a partir de esta doble afluencia, la del ideal normativo y la experiencia social, que es necesario entender los procederes de los individuos. No obstante, sostener que ideal y experiencia social son dos fuentes explicativas de los procederes aún es una respuesta insuficiente. Lo es porque resulta todavía necesario explicar la naturaleza de lo que se produce en este encuentro, en particular si, como un simple análisis lo muestra, cada una de ellas puede proveer de empujes en direcciones no complementarias o, aún más, directamente contrarias.

2 Para una lectura de este tipo, cf. Nino (2005).

3 Un ejemplo claro de estas lecturas son los enfoques socio-comportamentales. Para un ejemplo relativo a las normas genéricas y sexuales, cf. Gagnon (1992; 2008). 
Los procederes individuales, así, no pueden ser entendidos como respondiendo aisladamente a uno $\mathrm{u}$ otro, a ideal o a experiencia, pero tampoco como una combinación mecánica de ambos elementos. Para evitar una explicación mecanicista se requiere incorporar un tercer término que de cuenta de la función y el precipitado de la articulación de ambas dimensiones. Este tercer término es el sujeto.

Formulado de manera muy sencilla: la inteligencia de la acción no es nunca resultado de una relación directa entre las determinaciones sociales y culturales y la acción individual, sino que en todos los casos se trata de una relación mediada por el sujeto. Pero es indispensable definir más cercanamente a este sujeto. El sujeto que aquí se moviliza se coloca lejos de una visión sustantiva pero a igual distancia de una comprensión que lo hace flujos o nómade (Braidotti, 2000; Derrida, 1989). Precisamente para marcar la distancia con un sujeto sustancia y con un sujeto evanescente u nomádico, es que preferimos utilizar la noción de configuración de sujeto. ${ }^{4}$

La configuración de sujeto es producto de experiencias sociales y de la acción de ideales. Esta dualidad explica, por un lado, su carácter provisorio - porque siempre estoy obligado por las experiencias sociales y los avatares del ideal normativo a producir y reproducir el trabajo de mi configuración en cuanto sujeto. Por otro lado, permite dar cuenta del "aire de familia" conservado a lo largo del tiempo - en la medida en que los ideales inscritos a nivel individual y el sedimento de la experiencia social procuran una relativa estabilidad. La configuración de sujeto no está cristalizada, pero no está abierta a modificaciones infinitas. A pesar de su maleabilidad debemos contar con la resistencia del material, y ésta está hecha de las huellas de las experiencias y de la acción del ideal. Las configuraciones de sujeto dependen de la contingencia pero no están abandonadas al azar. Aunque son maleables no son volátiles.

La configuración de sujeto funciona como orientación y fuente de legitimación de los trayectos y actos individuales, lo que quiere decir, si seguimos el argumento hasta aquí expuesto que el sujeto que puedo ser se define en el interregno que es constituido por los ideales inscritos y lo que mi experiencia social me dice sobre las vías posibles, aconsejables y eficientes para presentarme y conducirme en lo social.

Las configuraciones de sujeto, así, no son meramente reflejos de ideales normativos. Ellas son resultado del trabajo del individuo para producirse como sujeto en la articulación de ideales y experiencias sociales. Por otro lado, estas

4 Para un trabajo detallado en torno a esa noción ver Araujo (2009a; 2009b). 
configuraciones no son puro efecto pasivo unificado en una lógica exterior. ${ }^{5}$ Hay que considerarlas ciertamente un precipitado, aunque radicalmente maleable, pero, y al mismo tiempo, acción constante y potencialmente transformativa del trabajo individual de articulación de ideal normativo y de las experiencias sociales.

Pero, llegado a este punto se imponen ciertas preguntas: ¿se trata de todo y cualquier ideal normativo? ¿Tiene toda experiencia social la capacidad de intervenir en estas configuraciones?

Veamos con detalle cada una de estas interrogantes.

Los ideales no actúan de manera mecánica en la conformación y acción de los individuos concretos. Ello explica la acción siempre desigual y plural de los ideales cuando se los piensa desde la perspectiva individual. No todo ideal normativo consigue hacer el camino de su inscripción individual, es decir, no todo ideal normativo tiene un carácter preformativo respecto a los procederes individuales. Es así que en lo que concierne a la configuración de sujeto es indispensable considerar que no se trata de la actuación de cualquier o todo ideal. Se trata de aquellos que, retomando las propuestas psicoanalíticas (Freud, 1915; 1921; Lacan, 1966), han alcanzado su inscripción en el individuo. Un proceso que no puede ser entendido como directo y sin mediación. De este modo, en el estudio de los ideales normativos la primera cuestión que hay que enfrentar es si, en qué medida y bajo qué modalidad ellos han encontrado o no un camino de inscripción individual. Dicho de otro modo, y para apoyarnos en términos psicoanalíticos si y de qué manera hacen parte del Ideal del Yo, esto es, del lugar "desde el que nos miramos de modo que nos resultamos amables, dignos de amor" (Zizek, 1992, p. 147).

Así como no hay una relación directa entre ideal normativo y proceder individual, también es necesario entender que el papel de la experiencia social pasa por una suerte de proceso de filtrado.

La experiencia social se constituye a partir de acontecimientos que son elaborados según diferentes regímenes (hermenéuticos o gramático sensoriales), pero, como es evidente, no todas las experiencias tienen un peso similar para los individuos, como tampoco cada una de ellas es suficiente para orientar nuestras acciones. Al mismo tiempo, la dirección que toman nuestros actos sólo puede ser considerada como efecto de múltiples y variadas

5 En este punto la configuración de sujeto se aleja de las tesis que sostienen que el sujeto es generado en una relación de mera sujeción por medio ya sea de la intervención productiva de discursos o dispositivos como Foucault lo ha propuesto $(1996$; 1995). Es decir, se distancia de un modelo que vincula al sujeto con la subjetivación haciendo equivalente, en el mismo movimiento, subjetivación y sujeción. 
experiencias. Así, no toda experiencia social tiene efectos sobre las maneras de orientarse y conducirse en lo social. Es, en rigor, el saber sobre lo social que proviene de la decantación de las diferentes experiencias sociales y de su diferencial impacto, lo que aporta a la inteligencia de los trayectos en lo social. Si del lado de los ideales, el Ideal del Yo funciona como mediación, del lado de la experiencia lo hace el saber decantado sobre lo social.

Para decirlo de la manera más precisa posible: el estudio de los individuos en su relación con la norma, implica dar cuenta de las lógicas y estrategias a partir de las cuales se orientan y conducen en lo social (si cruzan un semáforo rojo, si rechazan una oferta de corrupción, si movilizan recursos de influencia fuera de la ley, etcétera). Las configuraciones de sujeto son fuentes de orientación y legitimación de las acciones individuales y, por lo tanto, están en el lugar de dar cuenta de la inteligencia de los modos de actuación en lo social. Estas configuraciones se producen, mantienen y operan en el trabajo de articulación entre ideales normativos que han alcanzado su inscripción a nivel individual y el decantado de saber de la experiencia social particular. Es esta articulación permanente que da cuenta de la maleabilidad de las configuraciones de sujeto así como de la imposibilidad de considerar experiencia social e ideal normativo fuera de los efectos de su interacción capturada por el trabajo de su articulación.

Hecho el recorrido anterior podemos presentar ahora las preguntas que han orientado nuestro trabajo empírico: 1) del lado del ideal, ¿es el derecho un ideal normativo que ha alcanzado su inscripción a nivel individual en el caso de la sociedad chilena?, 2) ¿cuál es el saber decantado de la experiencia social que revelan los individuos pertenecientes a esta sociedad?, y 3) ¿cuáles son las configuraciones de sujeto que pueden identificarse, y qué dicen ellas de las modalidades privilegiadas de articulación de experiencias sociales e ideal normativo de derecho y sus efectos para los modos en que se encara la relación con la norma en Chile en el momento actual?.

Antes de abordar las respuestas obtenidas se requiere hacer un alto para dar cuenta de la manera en que la investigación fue realizada. Este decurso es particularmente importante por lo que el estudio de las relaciones de los individuos con las normas supone como desafío metodológico.

\section{Pensar los métodos}

Esta investigación partió de la pregunta por la manera en que el derecho como ideal normativo participaba o no en la regulación de las relaciones cotidianas entre las personas y entre éstas y las instituciones. Se interrogó así 
por el conjunto de elementos a partir de los cuales las acciones de los individuos resultaban inteligibles así como cuáles eran las formas de justificación y legitimación para el tipo de relación con la norma que ellos establecían.

Pero una vez elegida la vía del derecho para acercarnos a la investigación empírica de las normas en la sociedad chilena actual, la pregunta que se debió enfrentar fue ¿cómo capturar el trabajo de los individuos en el contexto de las relaciones con la norma? ¿Cómo acercarse simultáneamente a los modos concretos en que se regulan las relaciones sociales y a los fundamentos que orientan esos actos?

Para responder estas inquietudes la mayor parte de los métodos disponibles evidenciaban limitaciones. Las técnicas de investigación cualitativa tradicionales contenían el riesgo de conducir a que el material estuviera signado por una explicitación del orden de las normas fuertemente atado a una visión idealizada de ésta y de la relación con ellas. Resultaba por tanto necesario encontrar una vía que permitiera sortear una posición de enunciación condenatoria de conductas consideradas desviantes y una construcción defensiva del yo frente a las expectativas proyectadas en el investigador(a).

El problema principal consistió en producir, entonces, un nuevo dispositivo de investigación ${ }^{6}$ que nos permitiera escapar de este riesgo, y al mismo tiempo autorizara a capturar prácticas concretas desarrolladas en las interacciones sociales e identificar las lógicas subyacentes a las mismas. Esto es, recrear las modalidades de las prácticas materiales, impulsando a una pérdida de distancia del individuo con su acción. Por el otro dar el espacio para la reflexividad sobre las mismas, promoviendo la distancia del individuo con su acción.

En breve, el nuevo dispositivo de investigación debería permitir: (1) capturar prácticas y escenas cotidianas, lo suficientemente comunes como para que fueran reconocidas colectivamente como elemento relevante de la experiencia social; (2) desentrañar en estas escenas las certezas colectivas sobre los modos efectivos (no idealizados) de funcionamiento de la norma y de las relaciones con ella; (3) aprehender las interpretaciones acerca de las lógicas que explican un tal funcionamiento social y que subtienden a los procederes de los individuos, y (4) reconstruir los entramados de sujeto complejos y múltiples que orientan la actuación individual en lo social.

El dispositivo de investigación que se produjo lo denominamos Grupos de Conversación Dramatización (GCD). Se trata de un dispositivo que, pensado para responder a la pregunta central de esta investigación, combina

6 Para una discusión detallada, ver Araujo (2009b). 
la técnica de los grupos de discusión y la técnica de la dramatización aplicada a la investigación social, y se nutre de la estrategia metodológica de la investigación participante.

Los grupos fueron acomodados en salas acondicionadas con sillas, grabadoras de audio y una cámara de filmación fija ubicada de manera visible. Las sesiones duraron entre una hora y media y dos horas. Participaron en cada ocasión dos miembros del equipo de investigación cumpliendo respectivamente las funciones de moderación y observación. El desarrollo de los GCD se dividió en cuatro momentos.

En el primer momento, los y las participantes fueron invitados a narrar algún episodio de su vida cotidiana en el cual hubieran sentido que sus derechos no fueron respetados y que a su juicio representara de alguna manera un "ejemplo paradigmático" de este tipo de situaciones. En el segundo momento, se les solicitó la construcción colectiva de una escena en la que se tocara una historia real o ficticia de vulneración de derechos para ser representada luego frente al equipo de investigación. La producción de la escena debía incluir la identificación de los personajes así como necesariamente un desenlace. En este momento los miembros del equipo de investigación abandonaron la sala, pero los equipos de registro se mantuvieron activados. En cada uno de los casos ocurrió que el grupo discutió hasta conseguir un consenso sobre la trama de la escena y el reparto de personajes. En ningún caso se escribió realmente un guión. Los grupos confiaron en que los personajes sabrían desarrollar sus parlamentos. El tercer momento fue el de la dramatización propiamente dicha. Los grupos presentaron a los personajes y a los actores encargados de encarnarlos y representaron la escena frente al equipo de investigación. En todos los casos produjeron de manera espontánea escenas en las que todos los y las participantes tuvieran un rol y en casi la totalidad de los casos un parlamento. Lo gestual, la relevancia de lo corporal y la literalidad en el lenguaje son elementos adicionales y extremadamente importantes que aportan las dramatizaciones al análisis. El cuarto y último momento, consistió en la profundización de la escena recreada. En él se estimuló la reflexividad del grupo para identificar las lógicas inherentes a la escena y a la actuación de los personajes. Asimismo se promovió la búsqueda de desenlaces alternativos.

Tres grandes criterios fueron contemplados para la composición muestral de la investigación: socioeconómicos, género y generación. Lo anterior se fundamentó en la suposición que las experiencias sociales no son homogéneas sino que se declinan en función de estos criterios. No porque haya una relación lineal entre dimensión normativa y posición social, como ya hemos discutido, sino porque es posible considerar que ellos se asocian con mayores 
posibilidades de exposición a cierto tipo de experiencias sociales, un elemento que aporta a definir las posibilidades de configuraciones de sujeto que se abren para cada cual.

\section{El ideal normativo de derecho en su encuentro con la experiencia social}

La peculiaridad de los modos de habitar lo social en cada uno de los sectores estudiados, á determinada en buena medida por la magnitud en que las experiencias sociales han conseguido horadar o conviven con una cierta preservación del ideal. proceso en el cual, como lo hemos observado a lo largo de toda la investigación, se diseña un fuerte contraste entre los individuos en función básicamente de criterios socioeconómicos, de género y de grupo etáreo. Pero, de estos atributos es sin duda el clivaje entre los diferentes sectores socioeconómicos el que mejor permite comprender las maneras efectivas como se da la relación con las normas en el Chile contemporáneo.

\section{Los sectores de menores recursos}

En el caso de los sectores de menores recursos, lo que se revela es un ideal normativo significativamente debilitado por la masiva acción de la experiencia social que pone en entredicho la capacidad y la legitimidad de éste en la regulación social.

En este marco, la desmentida de sujeto es una experiencia central que deben enfrentar en sus interacciones cotidianas, especialmente con individuos e instituciones que se ubican, en el paisaje imaginario social, en posiciones más aventajadas que las que ellos ocupan.

Alguien se imaginó crear ese cuento de "Pitéate un flaite", y eso lo único que te está diciendo es pitéate un popular, un poblacional o un poblador (Hombre, mixto, adultos jóvenes). ${ }^{?}$

"Pitéate un flaite", es leído por este hombre poblador como un indicativo de la violencia de la sociedad contra los pobres. El flaite, aquel que hay que "pitearse", hacer desaparecer, es "un popular, un poblador, un poblacional". Es el borramiento, el rechazo, la desaparición violenta, lo que es adjudicado a la sociedad con respecto a los "poblacionales". "Desde allí estás siendo marginado" (Hombre, mixto, adulto joven), concluye. Es el margen, allí donde

El "Pitéate un flaite" al que hace referencia la cita fue un motivo inventado y difundido por una radio santiaguina. El "flaite" es una palabra de significados varios, pero que de manera general se puede decir que identifica a jóvenes que adhieren a un tipo de cultura juvenil asociada a las "poblaciones", zonas residenciales de sectores de menores recursos. 
no se sea visible, el lugar que les es indicado. Ser pobre es estar en el lugar de lo no deseado.

... Hay cuestiones que tienen que ver con la cuestión clasista que hay con esta cosa de la visión de los pobres eso a nosotros mismos como pobres nos hace menoscabarnos y sentirnos menos y tener la necesidad de ser otra cosa, es como una negación de la identidad de ser pobre, o sea, si soy pobre, soy marginal, soy delincuente, y la verdad es que yo no lo soy: soy pobre. Sin embargo, toda esta carga social me niega mi identidad (Hombre, mixto, adulto joven). ${ }^{8}$

La dimensión de clase es un elemento explicativo central para sus experiencias sociales. Su condición de pobres, la que es sustantivizada, los coloca, con un grado alto de fijeza, en una posición de extremada fragilidad y exposición a los abusos o discriminaciones de las clases más beneficiadas, lo que se resume en el continuo efecto de borramiento de sujeto del que testimonian.

Allí hay otra cuestión súper puntual de negación de la pobreza. No existe el pobre acá, nosotros cómo nos vamos a sentir bien si por todos los medios de comunicación nos dicen que estamos súper bien, nosotros somos bacanes en América Latina, no sé, llegamos allí y vemos tremendo metro, sin embargo, llego a la esquina de mi casa y veo tres o cuatro cabros ${ }^{9}$ botados, los conocí de cabros chicos y ahora los veo botados (Hombre, mixto, adultos jóvenes).

La experiencia social, así, pone en entredicho el ideal normativo de derecho, y su fundamento, el principio de igualdad. Lo hace de tal manera que la lectura de lo que les toca vivir deja de ser hecha en términos de vulneración de derechos, como es el caso en los sectores medios, para ser leído básicamente en términos de discriminación. El rasgo fundamento de su discriminación es, tal como no dejan de evocar, el ser "pobres". Las fuentes de discriminación por ser pobre se encarnan en varios factores. Por un lado, en la apariencia, el dinero y los signos de pertenencia (familiares o comunales). Por el otro, en la asociación entre pobreza, violencia y delincuencia. Finalmente, en las variadas experiencias de abuso de poder al que son expuestos y empujados cotidianamente (el trabajo, la escuela, el transporte público, la relación con los vecinos).

Detengámonos por razones de espacio solamente en dos de los factores que contribuyen a las lógicas erosivas de la noción de derecho: el dinero y la violencia.

8 Por razones de espacio, las referencias al material en este artículo no incluyen las escenas dramatizadas y se concentran en los momentos de conversación y auto reflexividad. Para una presentación analítica que incorpora el material de las dramatizaciones ver Araujo (2009b).

9 "Cabros" jóvenes en el argot popular. 
En el caso del dinero, se trata del lugar de éste en el marco de una lógica privatizante y mercantil que se impone en el país, la que incorpora todos los intercambios y bienes sociales, incluidos los básicos como salud y educación, como bienes de consumo (Moulian, 1997). En virtud de ella, y dada la legitimidad de esta lógica, los derechos aparecen condicionados en el marco de una relación mercantil. Se tiene derechos si se paga, es la expresión que podría condensar este modo de comprender la vida social. Desde esta perspectiva, la gratuidad aparece significada como un beneficio discrecional. En cuanto "beneficiario" no es del orden de los derechos de lo que se trataría sino de una especie de don o favor.

... Pero es que dicen. "tú no estai pagando aquí, tú pagas y andas como quieras" porque estás pagando, pero aquí no pagas es gratis (Hombres, jóvenes).

La asociación dinero-derechos aparece así como un aspecto relevante que conforma la percepción que los pobres no serían "auténticos" sujetos de derecho así como que, en consecuencia, existiría una cierta ilegitimidad en sus demandas. En este punto la lógica mercantil se alía con la creciente desigualdad (Vergara y Ottone, 2007). El orden de derecho muestra su debilidad, y en consecuencia este ideal normativo es puesto fuertemente en cuestión.

Ahora el caso de la violencia. La violencia y su íntima asociada, la droga, son evocadas como parte del paisaje cotidiano de los sectores de menores recursos. La violencia amenaza su integridad física y moral. Para las mujeres ella toma la forma de violencia sexual, una dimensión extendida y fuertemente denunciada y reclamada por las mujeres más jóvenes. El cuerpo y la arbitrariedad del otro sobre el propio cuerpo son temas álgidos que pueblan la experiencia social de estas mujeres. La impunidad y la incapacidad de detener la violencia es una evidencia que es interpretada como un fracaso de la regulación de las relaciones sociales. Esto es, es leída como la insuficiencia para cumplir con la función principal de la ley y del orden de derecho que es la protección y precisamente del más débil. La justicia es considerada como blanda. Carabineros, la institución encargada de la protección de la población, es evaluada como ineficiente y, aunque indispensable, es muchas veces considerada como enemigo y una amenaza a la propia tranquilidad. Esta evidencia tiene como consecuencia no sólo el descrédito del orden de la ley y el derecho sino que la aparición de tendencias que propugnan o reconocen y avalan la existencia de salidas individuales y/o colectivas al margen del orden de la ley (tomar la ley por las propias manos). 


\begin{abstract}
Sí, hay grupos que pueden hacerlo mejor que nosotros, tienen los recursos, tienen la ley que los apoya para poder arreglar cosas, y si (uno) ve que no lo hacen, a uno le da impotencia, le dan ganas de decir "bueno si no toman la justicia, la voy a tomar yo por las mías". Entonces cuando uno empieza a hacer eso, la gente mira "ah!, este vecino está tomando la justicia por sus manos, no está bien, hay organismos que se encargan de hacer eso". Pero si esos organismos no hacen nada, ¿quién nos va a defender? (Hombres, jóvenes).
\end{abstract}

De esta manera, la acción regulatoria del derecho es desdecida con tanta frecuencia, percibida tan a distancia, que se ofrece sólo con mucha dificultad como un elemento para su configuración de sujeto. La acción del ideal normativo se encarna, desde su punto de vista, sólo para los otros, en una definición claramente de clase. El derecho, en este caso, su no vigencia o su vigencia, es lo que define la frontera entre ellos, "los pobres", y los otros. La norma está hecha para los otros.

El derecho en los sectores de menores recursos, entonces, tiene un carácter impuesto, y es percibido como una herramienta más entre otras del conjunto posible de instrumentos a movilizar en sus estrategias para actuar en los social más que como un elemento estructurante de sí y de la sociedad. Como consecuencia de la falta de vigor del ideal de derecho, una gama mucho más amplia de nociones son convocadas para dar cuenta de su experiencia. En particular, se encuentra una lectura de lo social que moviliza más la noción de justicia. Establecer la regulación de lo social prioritariamente a partir de la noción de derecho, los coloca en la posición de actores que juegan un juego que no les compete del todo. Ello porque para ellos el sentido y la legitimidad del derecho como ideal normativo para la regulación social es un paso previo no alcanzado. La falta de legitimidad del ideal de derecho, sostenido en lo que sus experiencias sociales les dicen, es lo que da cuenta del sentimiento de extranjeridad que los invade.

\title{
Los sectores medios
}

En los sectores medios el derecho aparece como clave principal de lectura de lo social. Una enorme pluralidad de situaciones e interacciones, que van desde las relaciones contractuales hasta las interacciones cotidianas más informales encuentran su significación y valor a partir de lo que la clave de derecho aporta como horizonte interpretativo. El ideal adquiere incluso un carácter desmedido.

Cuando pasas el pase escolar en la micro, ahí te pasan a llevar los derechos cuando el chofer te insulta, o cuando no querís dar el asiento que está designado para minusválidos porque estai cansado, 
o también en el cuento laboral (...) Creo que los derechos se pasan a llevar día a día, uno mismo al interrumpirte por ejemplo, me estoy equivocando y te estoy pasando a llevar (tus derechos) (Hombres, jóvenes).

Los individuos hacen uso de este argumento aún en relación con situaciones no regidas por éstos, como lo muestra la cita. Ellos son percibidos como potencialmente actuantes en todos los ámbitos de su experiencia y relación, aún en aquellos orientados por ejemplo, por principios éticos o de valor de uso y costumbre.

En los sectores medios, así, el ideal normativo de derecho se encuentra más preservado, pero la preservación del ideal se vincula menos con el carácter de la experiencia social (pues ésta aparece también aquí horadando al ideal normativo) que con la función que ha adquirido el propio ideal. Se aferran al ideal de derecho, porque éste se ha constituido en un elemento central ofrecido para la configuración y legitimación de sujeto. El ideal de derecho es un elemento de definición de sujeto. Es un recurso extremadamente maleable, un dispositivo colectivo, de legitimación y defensa personal, pero también un criterio privilegiado de evaluación moral. Las categorías de evaluación moral asociadas a la injusticia (el acto justo o injusto), o el bien (si mis actos son correctos o incorrectos), han cedido en una medida no despreciable paso a la noción de derecho para el cumplimiento de esta función.

Ahora bien, resulta indispensable insistir que esta inflación del ideal normativo de derecho se da aún cuando con frecuencia no se actualice en la orientación de los actos de los individuos. Éstos se presentan dependientes de lógicas otras a lo que reconocen como ideal de actuación regido por el derecho. Es precisamente esta paradoja constituida por la función extremadamente importante que cumple el ideal para la legitimación de sujeto y su disminuida potencia para orientar los actos de hombres y mujeres en sus interacciones cotidianas, lo que constituye el corazón de la relación con las normas en los sectores medios chilenos. Junto con un ideal extendido en sus funciones hermenéuticas y de sostén subjetivo y moral, se revela que la orientación de los actos se da en función de lógicas que contravienen el ideal.

Las experiencias sociales son también para este sector guías primordiales en la orientación de sus actos y trayectos, y lo que ellas muestran es la vigencia de dos lógicas centrales en lo social: la lógica del privilegio y la de la confrontación de poderes.

La lógica del privilegio se expresa en el reconocimiento que el trato diferencial según signos de distinción social, el recurso a los medios ilegales, la movilización de las influencias de los amigos o los conocidos están presentes 
en las prácticas sociales. Esta lógica erosiona el principio de igualdad, y es esta fractura la que se pone en evidencia en sus experiencias relativas al funcionamiento de las instituciones sociales, a las interacciones entre el estado y los individuos o entre los individuos entre sí en sus prácticas cotidianas.

La sociedad actual construye la idea de que todos somos iguales y esa es una falacia tremend (Hombres, jóvenes).

¿Pero qué se entiende por igualdad? La igualdad es convocada en las narraciones menos en su sentido abstracto jurídico, o desde el nivel estructural económico (aunque lo segundo está mucho más presente que lo primero) y mucho más desde una perspectiva fuertemente vinculada a las experiencias en las interacciones sociales. Somos todos iguales en la medida en que recibimos el mismo trato de cara a la norma en las interacciones cotidianas independientemente de la posición social, los signos de distinción que podamos movilizar o la relación al poder que podamos ostentar.

Frente a ello, el privilegio legitima las diferencias basadas en las jerarquías consideradas naturales, y es uno de los aspectos principales a los que se opone la igualdad desde una perspectiva histórica y sociológica (Dumont, 1983). El privilegio bloquea la posibilidad del establecimiento de un espacio común entre los individuos más allá de sus particularidades. Él transforma diferencias en desigualdades de status y condición. Interviene desordenando el campo de relaciones y obstaculizando la generación del espacio común (Da Matta, 2002), y en el caso de la sociedad chilena, testimonia de la vigencia de una estructuración jerárquica de la sociedad (Bengoa, 2006; Larraín, 2001; Salazar y Pinto, 1999b) que interviene de manera activa como obstáculo para la construcción de un espacio que enlace a los individuos.

...Y como tú actuai para tener lo que necesitas, de algún modo,
te sientes impotente, porque te sientes impotente frente a esas
jerarquizaciones, porque tú no sabes el lugar que ocupan, entonces
de algún modo, igual es complejo poder gritar, poder reclamar
tus derechos... porque sabes el lugar donde estas ubicado...no
tienes estos tíos, conocidos, no tienes más poder que ese, digamos
(Mixto).

El poder, por su parte, es el gran tema en los sectores medios. La vida social es de manera concreta y vívida un entramado complejo y a la vez exigente de poderes.

(La sociedad) esté llena de escalones, estai acá, pero hay alguien en un escalón más arriba, y más allá está tu papá y tu tío que está un escalón más arriba. La sociedad está estructurada en base a estas cosas de poder (Hombre, mixto, jóvenes). 
El poder y su funcionamiento, se constituye, así, en el pivote de la comprensión de lo social. Es identificado como el elemento por excelencia que da cuenta de la erosión del orden de derecho, pero es al mismo tiempo percibido como el recurso de mayor valor y utilidad social. El poder, adecuadamente movilizado, permite traspasar toda barrera normativa, acceder a los recursos, evitar la discriminación, alcanzar las metas. Pero, además, la experiencia vivida lo revela en la faz en la que se confunde y aún se fusiona con el orden del abuso. Poder y abuso, aparecen inexorablemente entrelazados. El nombre propio que toma el poder en su traducción de las experiencias sociales es abuso, y es éste el estribillo recurrente y dolorido de la narración sobre la vida social.

Es fácil entonces comprender que los recursos de poder son percibidos como decisivos en las relaciones y los intercambios sociales.

En ese asunto estamos de acuerdo [...] que la vulnerabilidad tiene que ver con la cuota de poder que tú puedes manejar (Mujer, mixto, jóvenes).

No obstante, en el caso de los sectores medios, las experiencias sociales no tienen el carácter masivo, rígido, y unilateral de amenaza a lo más básico del sujeto. Para estos sectores, los resquicios sociales son más numerosos y asequibles, pero dependen de la capacidad de movilizar poder (influencias, recursos materiales o simbólicos, entre otros).

Siendo lo social un lugar de confrontación al mismo tiempo que un campo en el que resulta vital encontrar e instrumentalizar los resquicios sociales que se ofrecen, hacer uso de una fina semiología social resulta indispensable. Lo que se intenta ver privilegiadamente en el encuentro con el otro es su ubicación en el mapa de poder. Para defenderse de él, para encontrar la respuesta adecuada, para exhibir el propio poder, o para conseguir, como dice un participante, "lo que necesitas". La "tasación del otro" se dará en las unidades de medida que son connotadas con el uso del par significante "fuerte-débil". El otro es, entonces, sobre todo objeto de ponderación permanente pues de ello resulta el tipo de actitud y de relación a tener, sus posibilidades y sus límites. Es esto lo que vale en la lógica de la confrontación de poderes.

El derecho en estos sectores, entonces, tiene una función estructurante y de sostén de sujeto central, pero las experiencias sociales testimonian de la actuación de otras lógicas en lo social que contravienen al ideal a las que los individuos adhieren. Las consecuencias son varias. Primero, la desmesura del ideal, implica un cierto carácter monocorde en los modos de tratamiento de la justicia y en la evaluación de las interacciones sociales. Segundo, el trabajo permanente de justificación moral que supone que la actuación social 
se desarrolle en la coyuntura paradojal descrita impone una relación oblicua (e incluso negadora) con los propios actos. No es azar que, como lo muestran nuestros resultados, la configuración de sujeto más crítica frente a este doblez, afirme una posición ética fuertemente individual en la que lo está en juego es el reconocimiento de la propia participación en la erosión de los principios consensuados para la regulación de la vida social. Finalmente, la agudeza semiológica requerida en la relación con el otro, definido básicamente por la cuota de poder que posee, supone una mirada privilegiadamente dirigida hacia los lados o hacia lo alto de la pirámide social imaginada. La ceguera respecto a los otros, "los pobres" denunciada por los individuos de los sectores populares se confirma y encuentra su explicación desde este lado de los testimonios. Si en los sectores populares, es la extranjeridad la relación principal con respecto al juego social regulatorio basado en el derecho como ideal normativo, en el caso de las clases medias, las exigencias que provienen del encuentro ideal y experiencias sociales los conducen a una especie de enclaustramiento y reducción del campo visual. En todos los casos, la relación con la norma es un campo de pugna y negociación permanente.

\section{La división moral: las configuraciones diferenciales de sujeto}

¿Cómo se organiza, entonces, en estos entramados la relación de los individuos con la norma? ¿Cuáles son los rasgos de las configuraciones de sujeto a partir de las que orientan sus actos?

Las configuraciones de sujeto encontradas en cada caso como fruto del trabajo del individuo pueden ser leídas en el marco de la relación entre experiencias sociales e ideal. ${ }^{10}$ Son versiones que se dan, de un lado, en el de los sectores de menores recursos, en el contexto de un ideal debilitado y una experiencia social que está signada por el borramiento de sujeto. Del otro sector, de un ideal desmedido en conjunción con una experiencia social que revela la vigencia de lógicas ajenas al ideal. Si de este último lado se trata de los efectos de una creencia traicionada, del primero encontramos una descreencia neutralizada instrumentalmente por las necesidades de transitar lo social. Si en las clases medias, se trata pioritariamente de un trabajo de justificación de las orientaciones de un sujeto cuya constitución se sostiene en el derecho y cuyos actos se alejan de él, en los sectores populares se trata

\footnotetext{
${ }^{10}$ Por razones de espacio no se realiza aquí una discusión exhaustiva de este punto. Basta mencionar aquí que se identificaron para cada caso cuatro tipos de configuraciones de sujeto. Para los sectores medios: sujeto pragmático-idealista, crítico, de la amargura, del exceso. En el caso de los sectores populares: sujeto pragmático, indignado, desencantado y antisistémico. Una discusión detallada en Araujo (2009b).
} 
de un arduo trabajo individual para producirse como sujeto en el contexto de experiencias de borramiento y sentimientos de extranjeridad.

La exigencia primordial en los sectores populares es al trabajo, arduo y constante de producirse como sujeto contra la arremetida de las experiencias cotidianas. En oposición a las afirmaciones usuales que indican la ausencia de "individuo" en estos sectores, nuestros resultados revelan el permanente trabajo de éstos en la producción de sí como sujetos, ya sea en la modalidad indignada, pragmática, antisistémica o aún en aquella más límite como la del desencanto.

En los sectores medios, en los que la dimensión básica de sujeto se encuentra preservada y se cuenta con ofertas ideales poderosas para su constitución en tanto tales, lo que se agudiza es más bien la necesidad del trabajo de justificación de sí. Este trabajo resulta indispensable para mantener el precario equilibrio existente entre su lealtad retórica pero constitutiva al ideal y su casi permanente traición a éste en las actuaciones cotidianas. De esta manera, por ejemplo, la configuración de sujeto pragmático se acompaña paradójicamente de resabios idealistas; la configuración del sujeto del exceso, que se materializa en abuso, encuentra su sostén precisamente en nombre de la ley y el derecho.

De esta manera, lo que se revela en la sociedad chilena es que aún cuando los individuos compartan en apariencia y en términos generales los mismos criterios de lo justo y del bien, ella se encuentra atravesada en su relación con las normas por una profunda división moral. ${ }^{11}$ Los sujetos que se constituyen se dividen entre sí en la medida en que, como lo hemos visto, no articulan de la misma manera la ecuación entre el ideal y la experiencia. Es alrededor de estos diferenciales de ecuación donde se inscribe la división moral. Ser de clase media o ser pobre no depende exclusivamente de un posicionamiento social objetivo (oficio, nivel de ingresos, lugar de residencia, nivel educativo) sino que es también el resultado de un autoposicionamiento subjetivo y normativo en la vida social. En breve: una manera de habitar lo social.

Este autoposicionamiento complejo entre grupos y al interior de los grupos ha tenido, por lo demás, una historia accidentada en la sociedad chilena, en la cual, sin embargo, es posible observar, una transformación de los lenguajes dominantes para designarse y designar al otro. A muy grandes rasgos, tres grandes tópicos pueden ser señalados como siendo particularmente significativos. En primer lugar, el clásico tema de la "civilización o barbarie"

${ }^{11}$ Entendemos el término "moral" como el conjunto de usos consuetudinarios que estructuran la vida social pero enmarcados por una exigencia deontológica (lo que debe ser) y por ende, finalmente, en torno a un juicio sobre el bien y el mal (Ricoeur, 1996). 
propio a las sociedades latinoamericanas (Sarmiento, 1961 [1845]). En segundo lugar, la contraposición aún hoy tan presente en Chile entre "cuicos" y "rotos", una y otra denominación, a pesar de sus temporalidades particulares, imponiéndose en el momento en que se consolida la presencia cultural y política de los sectores medios (Collier y Sater, 1999). En tercer lugar, como nos hemos esforzado en mostrar en este artículo, un clivaje social que se revela en el diferencial de maneras por los cuales los grupos sociales instituyen su relación con las normas.

El descreimiento justificado en el ideal normativo de unos, los "pobres" de los sectores populares, se estrella aquí contra la creencia, si bien puramente retórica no por ello menos constitutiva y referencial de los otros, los miembros de las clases medias. Se trata de un juego sutil de definiciones recíprocas que, no obstante expresarse en un lenguaje más abiertamente moral, no debe ser considerado menos político que los dos precedentes. Él refleja la tensión ordinaria de grupos sociales que en el contexto de los procesos de modernización y el empuje a la democratización que se han desarrollado en el país en las últimas décadas han sido instalados en un imaginario político común (Garretón, 2000), una tensión que resulta de las diferencias que se trazan en virtud de la magnitud y carácter de la inscripción del ideal normativo y de las experiencias sociales cotidianas diferenciales. Experiencias que revelan la preservación de lógicas jerárquicas, autoritarias, de desregulación del poder, privilegio, entre otras, con las que los individuos, hombres y mujeres, topan en sus más banales interacciones cotidianas y que como la gota que talla la roca cincelan tanto la imagen del mundo social como el perfil de la configuración de sujeto a partir de la cual se orientan en él.

Visto lo anterior es posible retornar a nuestro punto de partida. Como este trabajo ha pretendido poner en evidencia centrándose en el caso de Chile, es indispensable considerar que las tareas de democratización social y construcción de sociedades más justas requieren además de fuertes impulsos a la transformación jurídica e institucional poner el foco tanto en el peso de la cotidianeidad, en cuanto fuente privilegiada del saber sobre lo social, como en los sujetos encarnados que inevitablemente y en última instancia producirán y sostendrán estas tareas.

\section{Referencias}

ARAUJO, Kathya. Dignos de su arte. Sujeto y lazo social en el Perú de las primeras décadas del siglo XX. Madrid/Frankfurt: Iberoamericana, 2009a.

. Habitar lo social. Usos y abusos en la vida cotidiana en el Chile actual. Santiago: LOM, 2009b. 
. Transnationalisation et politiques publiques. Les processus d'institutionnalisation des agendas féministes. In: MARQUES-PEREIRA, Bérengere; MEIER, Petra; PATERNOTTE, David. Au-delà et en-deçà de l'Etat: le genre entre dynamiques transnationales et multi-niveaux. Louvain-la-Neuve: Academia Bruylant, 2009c. (en prensa)

BAUMAN, Zygmunt. Modernidad liquida. Buenos Aires: Fondo de Cultura Económica, 2003.

BECK, Ulrich; BECK-GERNSHEIM, Elizabeth. La individualización. Barcelona: Paidós, 2003.

BENGOA, José. La comunidad reclamada. Identidades, utopías y memorias en la sociedad chilena actual. Santiago: Catalonia, 2006.

BOURDIEU, Pierre; WACQUANT, Loïc. Respuestas por una antropología reflexiva. México: Editorial Grijalbo, 1995.

BRAIDOTTI, Rosi. Sujetos nómades, corporización y diferencia sexual en la teoría feminista contemporánea. Buenos Aires: Paidós, 2000.

COLLIER, Simon; SATER, William. Historia de Chile 1808-1994. Madrid: Cambridge University Press, 1999.

COSTA, Sérgio; MELO, Rurion; SILVA, Felipe. Sociedad civil, estado y derecho en América Latina: tres modelos interpretativos. In: ARAUJO, Kathya (Ed.). ¿Se acata pero no se cumple? Estudios sobre las normas en América Latina. Santiago: LOM, 2009. (en prensa)

DA MATTA, Roberto. Carnavales, malandros y héroes. Hacia una sociología del dilema brasileño. México: Fondo de Cultura Económica, 2002.

DE LA MAZA, Gonzalo. Los movimientos sociales y la democratización en Chile. In: DRAKE, Paul; JAKSIC, Iván (Eds.). El modelo chileno. Democracia y desarrollo en los noventa. Santiago: LOM Ediciones, 2002. p. 377-405.

DERRIDA, Jacques. La escritura y la diferencia. Barcelona: Anthropos, 1989.

DRAKE, Paul; JAKSIC, Iván (Eds.). El modelo chileno: democracia y desarrollo en los noventa. Santiago: LOM Ediciones, 2002.

DUMONT, Louis. Essais sur l'individualisme. Paris: Seuil, 1983.

FOUCAULT, Michel. Vigilar y castigar. México: Siglo XXI, 1996.

. Historia de la sexualidad. Tomo 1: La voluntad de saber. México: Siglo XXI, 1995 (1984).

FREUD, Sigmund. Duelo y melancolía. In: FREUD, Sigmund. Obras completas. Madrid: Biblioteca Nueva, 1974 (1915). p. 2091-2100.

Psicología de las masas y análisis del Yo. In: FREUD, Sigmund. Obras completas. Madrid: Biblioteca Nueva, 1974 (1921). p. 2563-2610.

GAGNON, John. La interacción de los roles genéricos y la conducta sexual. In: KATCHADOURIAN, Herant (Ed.). La sexualidad humana: un estudio comparativo de su evolución. México: Fondo de Cultura Económica, 1992. p. 265-288. 
. Les scripts de la sexualité. Essais sur les origines culturelles du désir. Paris: Payot, 2008.

GARRETÓN, Manuel Antonio. La sociedad en que vivi(re)mos. Santiago de Chile: LOM Ediciones, 2000.

GIDDENS, Anthony. Modernidad e identidad del yo: el yo y la sociedad en la época contemporánea. Madrid: Península, 1994.

GIROLA, Lidia. Anomia e individualismo. Madrid: Anthropos-UAM, Azcapotzalco, 2005.

GUZMÁN, Virginia. Las relaciones de género en un mundo global. Serie Mujer y Desarrollo, n. 38. Santiago: Cepal, 2002.

HABERMAS, Jürgen. Facticidad y validez. Madrid: Trotta, 1998 (1992).

. Teoría de la acción comunicativa. Tomo 2: crítica de la razón funcionalista. Madrid: Taurus, 1987.

KATCHADOURIAN, Herant (Ed.). La sexualidad humana. Un estudio comparativo de su evolución. México: Fondo de Cultura Económica, 1992.

LACAN, Jacques. Subversion du sujet et dialectique du désir dans l'inconscient freudien. In: LACAN, Jacques. Écrits. Paris: Seuil, 1966. p. 793-827.

LARRAÍN, Jorge. Identidad chilena. Santiago: LOM Ediciones, 2001.

MARTUCCELLI, Danilo. Cambio de rumbo. La sociedad a escala del individuo. Santiago: LOM, 2007.

MÉNDEZ, Juan; O’DONNELL, Guillermo; PINHEIRO, Paulo Sérgio (Eds.). La (in) efectividad de la ley y la exclusión en América Latina. Buenos Aires: Paidós, 2002.

NINO, Carlos. Un país al margen de la ley. Buenos Aires: Emecé, 2005.

MOULIAN, Tomás. Chile actual: anatomía de un mito. Santiago: LOMEdiciones, 1997.

O’DONNELL, Guillermo; SCHMITTER, Philip; WHITEHEAD, Lawrence (Eds.). Transitions from authoritarian rule: comparative perspectives. Baltimore: John Hopkins Univ. Press, 2000 (1986).

O’DONNELL, Guillermo. Las poliarquías y la inefectividad de la ley en América Latina. In: MÉNDEZ, Juan; O’DONNELL, Guillermo; PINHEIRO, Paulo Sérgio (Comps.). La (in)efectividad de la ley y la exclusión en América Latina. Buenos Aires: Paidós, 2002.

PARSONS, Talcott. El sistema social. Madrid: Alianza, 1982 (1951).

RICOEUR, Paul. Sí mismo como otro. México: Siglo XXI Editores, 1996.

SALAZAR, Gabriel; PINTO, Julio. Historia contemporánea de Chile. Volumen 2: Actores, identidad y movimiento. Santiago: LOM Ediciones, 1999b.

SARMIENTO, Domingo. Facundo o civilización y barbarie. Buenos Aires: Ediciones Culturas Argentinas, 1961 (1845).

SMUlOVITZ, Catalina; URRIBARRI, Daniela. Poderes judiciales en América latina: entre la administración de aspiraciones y la administración del derecho. Sao Paulo: IFHC, 2007. 
SORJ, Bernardo; MARTUCCELLI, Danilo. El desafio latinoamericano. Buenos Aires: Siglo XXI, 2008.

TAYLOR, Charles. Las fuentes del yo. Barcelona: Paidos, 1996.

TOLOZA, Cristián; LAHERA, Eugenio. Chile en los noventa. Santiago: Ed. Dolmen, 1998.

VERGARA, Carlos; OTTONE Ernesto. La desigualdad social en América Latina y el caso chileno. Estudios Públicos, Santiago, n. 108, p. 59-91, primavera 2007.

ZIZEK, Slavoj. El sublime objeto de la ideología. México: Siglo XXI, 1992.

Recebido em: 23/07/2009

Aprovado em: 15/10/2009 